\title{
Spinal epidural abscess: the importance of early diagnosis and treatment
}

\author{
A R Mackenzie, R B S Laing, C C Smith, G F Kaar, F W Smith
}

\begin{abstract}
Objectives-To remind clinicians of the dangers of delayed diagnosis and the importance of early treatment of spinal epidural abscess.

Methods-A review of the literature on spinal epidural abscess and a comparison of the published literature with local experience.

Results-Imaging with MRI or CT enables early diagnosis of spinal epidural abcess and optimal therapy is surgical evacuation combined with 6-12 weeks (median 8 weeks) of antimicrobial chemotherapy. Clinical features are fever, pain, and focal neurological signs and may be associated with preceding and pre-existing bone or joint disease. The commonest aetiological organism is $S$ aureus.

Conclusion-Early diagnosis and appropriate early antimicrobial chemotherapy with surgery is associated with an excellent prognosis.

(F Neurol Neurosurg Psychiatry 1998;65:209-212)
\end{abstract}

Keywords: spinal epidural abscess; diagnosis; treatment; MRI

Spinal epidural abscess is a rare but potentially devastating condition. When recognised and treated early the outcome is excellent. ${ }^{1}$ Late diagnosis or inadequate treatment may leave the patient with long term severe or disabling incapacity. The need for early diagnosis and the benefits of appropriate early antimicrobial chemotherapy with surgery are discussed.

Aberdeen Royal Infirmary, Aberdeen A R Mackenzie

R B S Laing

C C Smith

Department of Neurosurgery, Aberdeen Royal Infirmary, Aberdeen G F Kaar

Department of Radiology, Woodend Hospital, Aberdeen F W Smith

Correspondence to: A R Mackenzie, The Infection Unit, Aberdeen Royal Infirmary, Aberdeen AB25 2ZN, UK. Telephone 0044

1224 681818; fax 00441224 685307 .

Received 19 May 1997 and in revised form 26 November 1997

Accepted 2 December 1997

\section{Epidemiology}

Spinal epidural abscess is an uncommon condition with an estimated incidence of $0.2-2.0 / 10000$ hospital admissions, ${ }^{23}$ and a peak incidence in the sixth and seventh decades of life. ${ }^{3}$ At this hospital over a five year period we have seen eight patients admitted from the community with spinal epidural abcess, giving an estimated incidence of $0.25 / 10000$ admissions. Their median age was 61.5 (range 48-75) The disease is rare in children, with fewer than 90 cases reported. ${ }^{5}$ Conditions commonly associated with spinal epidural abcess include diabetes mellitus, intravenous drug misuse, chronic renal failure, alcoholism, and cancer. ${ }^{2-4}$

\section{Pathophysiology}

Most spinal epidural abcesses are thought to result from the haematogenous spread of bacteria usually from a cutaneous or mucosal source and this occurred in five of our eight patients. In the series by Baker et $a l^{2}$ haematogenous spread of infection was identified in $26 \%$ of cases, the sources of bacteraemia including furuncles, pharyngitis, and dental abscesses. Haematogenous spinal epidural abcess are primarily located in the posterior aspect of the spinal canal. ${ }^{6}$ The direct spread of infection into the epidural space from a source adjacent to the spine-for example, spondylitis or discitis-is also well described. ${ }^{78}$ In such cases the abscesses are often located in the anterior aspect of the spinal canal and are thought to originate from the adjacent vertebral body. Direct spread from a paraspinal abscess may also occur and was the infective origin in one of our patients. In a recent review of 43 cases of spinal epidural abcess, $44 \%$ had coexistent vertebral osteomyelitis. ${ }^{9}$ Vertebral osteomyelitis was present in one of our eight patients $(12.5 \%)$.

Postoperative abscesses account for $16 \%$ of all spinal epidural abcesses ${ }^{2}$ and epidural catheter insertion is another recognised predisposing factor. ${ }^{10} 11$ None of our patients had postoperative abscesses.

Blunt trauma is reported to precede the symptoms of spinal epidural abcess in 15\%$35 \%$ of cases $^{7}$ and it is postulated that trauma may result in the formation of an epidural haematoma which subsequently becomes infected. ${ }^{12}$ A history of recent trauma was recorded in two $(25 \%)$ of our patients although the source of bacteraemia, as is often the case, was neither obvious nor identified in either patient.

\section{Clinical features}

The typical features of spinal epidural abcess are recognisable clinically - notably fever, spinal pain and tenderness, and radiating root pain followed by limb weakness. Pain is the most consistent symptom and occurs in virtually all patients at some time during their illness. Spinal pain and fever are usually the only symptoms present before a precipitous neurological deterioration occurs ${ }^{13}$ and were the only features in two of our patients Most patients have major neurological signs before surgery ${ }^{5}$ which are thought to result from a compromised spinal cord vasculature rather than direct cord compression. ${ }^{14}$ When septicaemia dominates the clinical picture, as in two of our patients, whose presenting features included jaundice, fever, confusion, and raised fibrinogen degradation products, the neurological symptoms may go unnoticed. This may also be the case in patients confined to bed. In patients with chronic infection, 

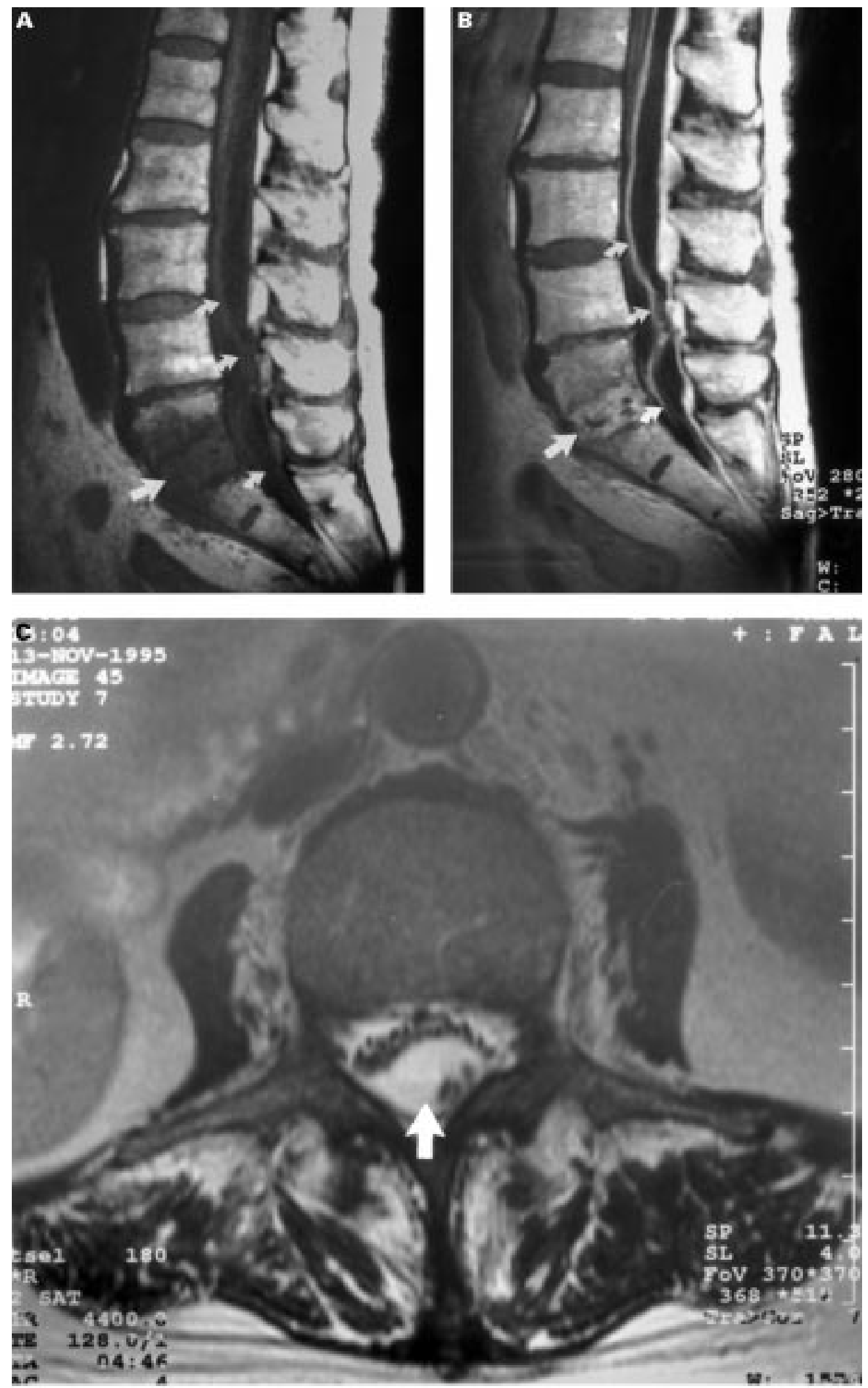

The superior quality of MRI over CT is demonstrated in this figure. Sagittal T1 weighted MRI of lumbosacral spine showing osteomyelitis of the L5 vertebral body (large arrow) with spinal epidural abcess L4-S1 anteriorly displacing the meninges (small arrows); (A) before contrast and (B) after contrast. (C) Axial MRI of L5 vertebra showing anterior displacement of the thecal sac by a spinal epidural abcess (arrowed).

constitutional symptoms of fever, weight loss, and systemic upset may predominate over the neurological syndrome ${ }^{10}$ and lead to late diagnosis and treatment.

\section{Location}

The described sites of spinal epidural abcess are variable. Only $20 \%$ occur anterior to the spinal cord. ${ }^{4}$ Our experience suggests that 
abscesses in the cervical or upper thoracic region are not uncommon - three of our eight patients had cervical or thoracic spinal epidural abcesses. Larger studies, however, describe a preponderance of lower thoracic and lumbar abscesses. ${ }^{15}$ The patients with lumbar abscesses may be misdiagnosed as having a herniated lumbar disc. ${ }^{16}$

\section{Microbiology}

Staphylococcus aureus was isolated in six of our eight patients $(75 \%)$. This is the most commonly recognised causative organism and accounts for $57 \%-73 \%$ of reported abscesses. ${ }^{2} 10^{14} 17$ In a review of five studies between 1930 and 1982, ${ }^{4}$ Danner and Hartman found that $S$ aureus was isolated in $62 \%$, other gram positive cocci cultured in $10 \%$, gram negative organisms in $18 \%$, and anaerobes in $2 \%$. After $S$ aureus, Mycobacterium tuberculosis is the most frequent cause and accounted for $25 \%$ of infections in the series reported by Kaufman et al. ${ }^{18}$ Streptococcus milleri has previously been reported as a cause of spinal epidural abscess ${ }^{19}$ and is recognised as an organism with a tendency to abscess formation. ${ }^{20}$ Haemophilus parainfluenzae, ${ }^{21} \mathrm{Bru}$ cella species, ${ }^{22}$ and Actinomyces israelii ${ }^{23}$ are amongst the many other isolates described. Disseminated fungal infections such as cryptococcosis, aspergillosis, and blastomycosis are rare causes and usually arise in immunocompromised patients. ${ }^{18}$ Aspergillus species are known to cause spinal epidural abcess in patients with AIDS. ${ }^{24}$

\section{Imaging}

The extent and location of an abscess is best visualised using MRI. Multiplanar imaging and visualisation of the soft tissues-including the spinal cord, paraspinal musculature, and the disc - confers a distinct advantage of MRI over CT and myelography ${ }^{25}$ and where available, should always be utilised (figure A, B, C).

\section{Antimicrobial therapy}

Empirical antimicrobial treatment of spinal epidural abcess should be bactericidal, start early, be delivered intravenously in high doses, and be continued well into the postoperative period. ${ }^{7}$ Initial treatment should be broad spectrum and include a combination of drugs with bactericidal activity against staphylococci, anaerobes, and gram negative organisms. If a methicillin sensitive $S$ aureus is isolated, successful treatment is possible with a first generation cephalosporin, ${ }^{4}$ a penicillinase resistant penicillin, ${ }^{26}$ combination vancomycin plus aminoglycoside, ${ }^{27}$ or trimethoprimsulphamethoxazole. ${ }^{28}$ Parenteral treatment should be continued for at least 4 weeks and may be prolonged for 8 weeks or longer if vertebral osteomyelitis is suspected. ${ }^{4}$ When no pathogen is isolated, broad "best guess" bactericidal cover is safest and best.

\section{Surgery}

Surgical treatment entails emergency evacuation of the pus with decompression of the spinal cord and nerve roots. In the presence of paraparesis, the outcome depends on the time that elapses from its onset to surgery. ${ }^{18}$ The longer the lapse the greater is the usual long term legacy.

\section{Prognosis}

The prognosis is dependent on the clinical and neurological condition of the patient at presentation and any delay in the diagnosis ${ }^{49}$ or instigation of appropriate antimicrobial treatment. Patients who present with overt sepsis do poorly. All such patients in one series died. ${ }^{30}$ Patients who are plegic preoperatively also do poorly, although this is time dependent. ${ }^{29}$ In the series of Danner and Hartman, ${ }^{4}$ patients with preoperative neurological defects present for less than 36 hours showed some improvement, whereas nine of 11 patients with deficits present for more than 36 hours before surgery did not. In the review by Maslen et al, ${ }^{29}$ patients paralysed preoperatively for greater than 12 hours did not recover neurological function and those paralysed for greater than 36 hours often died. In our series, the six patients who had developed neurological signs underwent surgery within 8 hours of their onset and had a good outcome. Some authors have found that the outcome of cervical abscesses is worse than those arising in thoracic or lumbar sites. ${ }^{14}$ In our series, cervical cases had good outcomes compared with those with thoracolumbar abscesses. Two cervical cases had MRI as the primary spinal investigation and at relatively early stages.

Although the duration of neurological deficit before surgery determines, in part, the neurological outcome, it is not the sole factor. It has been suggested that permanent axonal or cell body damage, for which we do not have a clinical indicator, has prognostic relevance. In our experience one patient who was paraparetic for only three hours before surgery remained paraparetic afterwards. By contrast, another patient who was paraplegic for seven hours made a virtually complete recovery after surgery.

\section{Mortality}

Although the mortality from spinal epidural abcess has improved from that described in the early reports, it has remained surprisingly consistent over the past several decades, at about $14 \% .^{4}{ }^{29}$ Mortality is clearly related to delay in instituting appropriate therapy, emphasising the need for early diagnosis and treatment. In addition, these patients should be followed up for several months - even after completion of antibiotic therapy, because of the spinal instability which may result from the infection or the necessary surgical intervention. ${ }^{1}$ There were no deaths in our series.

\section{Nutrition}

Patients undergoing these procedures often become malnourished and poor nutritional status is associated with increased postoperative complications. Close attention should therefore be paid to the perioperative nutrition and consideration given to preoperative and postoperative nutritional supplementation. ${ }^{31}$ 


\section{Conclusion}

The appreciable neurological recovery seen in some patients reflects the value of prompt diagnosis and early treatment. The key to successful management is early diagnosis, which requires that involved clinicians consider the diagnosis. Repeated spinal and neurological examinations are essential in any patient with an unknown focus of infection and when there is spinal pain or tenderness full investigation is warranted. The increasing availability of MRI may mean that earlier diagnosis and lower morbidity from this condition should become a reality in the near future.

1 Martin RJ, Yaun HA. Neurosurgical care of spinal epidural, subdural, and intramedullary abscesses and arachnoiditis. subdural, and intramedullary abscesses
Orthop Clin North Am 1996;27:125-36.

2 Baker AS, Ojemann, Swartz MN, et al. Spinal epidural Baker AS, Ojemann, Swartz MN, et
abscess. N Engl f Med 1975;293:463-8.

3 Hlavin ML, Kaminski KJ, Ross JS, et al. Spinal epidural abscess: a 10 year perspective. Neurosurgery 1990;27:17784.

4 Danner RL, Hartman BJ. Update of spinal epidural abscess: 35 cases and review of the literature. Rev Infect Dis 1987;9: 265-74.

5 Jacobsen FS, Sullivan B. Spinal epidural abscess in children. Orthopedics 1994;17:1131-8.

6 Calderone RR, Larson JM. Overview and classification of spinal infections Orthop Clin North Am 1996;27:1-8.

7 Verner EF, Musher DM. Spinal epidural abscess. Symposium on infections of the central nervous system. Med Clin North Am 1985;69:375-84.

8 Ozuna RM, Delamarter RB. Pyogenic vertebral osteomyelitis and postsurgical disc space infections. Ortho Clin North Am 1996;27:87-94.

9 Darouiche RO, Hamil RJ, Greenberg, et al. Bacterial spinal epidural abscess: review of 43 cases and literature survey. epidural abscess: review of
Medicine 1992;71:369-85.

10 Ericsson M, Algers G, Schliamser SE. Spinal epidural abscesses in adults: review and report of iatrogenic cases. Scand F Infect Dis 1990;22:249-57.

11 Pegues DA, Carr DB, Hopkins CC. Infectious complications associated with temporary epidural catheters. Clin Infect Dis 1994;19:970-2.
12 North JB, Brophy BP. Epidural abscess: a hazard of spinal epidural anaesthesis. Aust NZ F Surg 1979;49:484-5.

13 Rockney R, Ryan R, Knuckley J. Spinal epidural abscess. An infectious emergency. Case report and review. Clin Pediatr 1989;28:323-24.

14 Lasker BR, Harter DH. Cervical epidural abscess. Neurology 1987;37:1747-53.

15 Lanfermann $\mathrm{H}$, Heindel W, Gierenz $\mathrm{M}$, et al. The MR tomographic diagnosis of intra- and paraspinal abscess. Rofo Fortschr Geb Rontgenstr Neuen Bildgeb Verfahr 1996; 165:36-42. (In German.)

16 Ferree BA, Stambough JL, Greiner AL. Spinal epidural abscess. A case report and literature review. Orthop Rev 1989;18:75-80.

17 Still JM, Abramson R, Law EJ. Development of an epidural abscess following staphylococcal septicemia in an acutely burned patient: case report. F Trauma 1995;38:958-9.

18 Kaufman DM, Kaplan JG, Litman N. Infectious agents in spinal epidural abscess. Neurology 1980;30:844-50.

19 Gelfand MS, Bahktian BJ, Simmons BP. Spinal sepsis due to Streptococcus milleri: two cases and review. Rev Infect Dis 1991;13:559-63.

20 Andrews FW, Horder TJ. A study of the streptococci pathogenic for man. Lancet 1906;ii:708-13, 775-82, 852-5.

21 Auten GM, Levy CS, Smith MA. Haemophilus parainfluen$z a e$ as a rare cause of epidural abscess: case report and review. Rev Infect Dis 1991;13:609-12.

22 Paz JF, Alvarez FJ, Roda JM. Spinal epidural abscess caused by brucella: case report. $\mathcal{F}$ Neurosurg Sci 1994;38:245-9.

23 Kannangara DW, Tanaka T, Thadepalli H. Spinal epidural abscess due to Actinomyces israelii. Neurology 1981;31: $202-04$

24 Go BM, Ziring DJ, Kountz DS. Spinal epidural abscess due to Aspergillus sp in a patient with acquired immunodeficiency syndrome. South Med f 1993;86:957-60.

25 Smith AS, Blaser SI. MR of infectious and inflammatory diseases of the spine. Crit Rev Diag Imaging 1991;32:16589.

26 Firsching R, Frowein RA, Nitter K. Acute spinal empyema. Acta Neurochir (Wien) 1985;74:68-71.

27 Bader B, Labrune P, Zerah M, et al. Traitment medical d'une epidurite a staphylocoques. Arch Fr Pediatr 1986;43. 335-6.

28 Bouchez B, Arnott G, Delfoss JM. Acute epidural abscess. $\mathcal{F}$ Neurol 1985;231:343-4.

29 Maslen DR, Jones SR, Crisplin MA, et al. Spinal epidural abscess: optimizing patient care. Arch Intern Med 1993;153: 1713-21.

30 Redekop GJ, Del Maestro RF. Diagnosis and management of spinal epidural abscess. Can F Neurol Sci 1992;19:180-7. 31 Kleine JD, Garfin SR. Nutritional status in the patient with spinal infection. Orthop Clin North Am 1996;27:33-6. 